\title{
Near miss and mortality audit of women with postpartum hemorrhage (PPH) in a tertiary care center in North India: a cross-sectional study
}

\author{
Manu Shukla, Vinita Das, Smriti Agrawal, Anjoo Agarwal, Amita Pandey \\ Corresponding author: Dr. Smriti Agrawal, Department of Obstetrics \& Gynecology, King \\ George's Medical University, Chowk, Lucknow, Uttar Pradesh, India; \\ Email : drsmritijainagrawal@gmail.com
}

Distributed under Attribution-Non Commercial - Share Alike 4.0 International (CC BY-NC-SA 4.0)

\begin{abstract}
Objectives: To analyze the medical and social risk factors for maternal mortality and near miss in women with postpartum hemorrhage. Methods: It is a cross sectional study organized in department of obstetrics and gynecology, King George Medical University, Lucknow, India. Five hundred women who developed postpartum hemorrhage (PPH) in the hospital or referred with PPH were enrolled in study. Data was collected by a structured questionnaire which included demographic profile, medical and social risk factors, cause and type of PPH, interventions and management done. Maternal near miss (MNM) cases were identified as per WHO 2009 criteria. Results: Atonic PPH was the commonest type of PPH. Severe anemia (OR-2.35, 95\%CI 1.58 - 3.61, p value- 0.001) was significantly associated with maternal mortality. Jaundice (OR-31, 95\%CI 9.05-109.4, p value- 0.023), and previous cesarean (OR$2.66,95 \%$ CI 1.22- 5.46, p value- 0.003 ) were found to be significantly associated with MNM. Social risk factors like lack of awareness (OR-4.63, 95\%CI 2.43-8.83, p value <0.001), lack of transportation (OR-7.59, 95\%CI 4.48-12.86, p value $<0.001$ ), lack of infrastructure (OR-5.30, 95\% CI 3.18- 8.82, p value <0.001) and lack of trained health professional (OR-7.35, 95\%CI 4.20-12.60, p value $<0.001)$ were found to be significantly associated with mortality. The near miss to mortality ratio was 1.01:1 Conclusions: Reduction of maternal morbidity and mortality due to PPH needs multipronged approach of improving antenatal services, timely recognition and management of risk factors. Enhancing emergency obstetric services at periphery with better transport and referral will help to reduce preventable deaths from PPH.
\end{abstract}

Keywords: Maternal health, postpartum hemorrhage, social factors, near miss.

Postpartum hemorrhage (PPH) is defined as blood loss of $500 \mathrm{ml}$ or more from the genital tract within 24 hours of giving birth to the baby. Postpartum hemorrhage, an obstetrical emergency, constitutes a major health risk for the women giving birth and is one of the leading causes of maternal death in both developed and developing countries. It affects $2 \%$ of all women who give birth. PPH occurs in $4 \%$ of all vaginal deliveries and $6 \%$ of all cesarean deliveries ${ }^{1}$. A systematic review estimated prevalence of PPH at 10.5 percent in Africa, 8.9 percent in Latin America, 6.3 percent in North America and Europe, and 2.6 percent in Asia ${ }^{i}$. As per WHO, 25\% of maternal deaths are due to $\mathrm{PPH}$.

The importance of recognizing PPH which may lead to long term morbidities like anemia, multi-organ dysfunction, renal failure and its impact on psychological health of the patient cannot be overlooked. The near miss audits are gaining significance as they reflect the health facilities in a country. WHO defines maternal near miss (MNM) as a woman who nearly died but survived a complication that occurred during pregnancy, childbirth or within 42 days of termination of pregnancy. The severe morbidity to death ratio reflects the standard of maternal care. The disparity is

Received: $27^{\text {th }}$ July 2020, Peer review completed: $19^{\text {th }}$ September 2020, Accepted: $1^{\text {st }}$ October 2020.

Shukla M, Das V, Agrawal S, Agarwal A, Pandey A. Near miss and mortality audit of women with postpartum hemorrhage $(\mathrm{PPH})$ in a tertiary care center in North India: a cross-sectional study. The New Indian Journal of OBGYN. 2021; 8(1): 52-6. 
evident in developed nations where the ratio is $117-223: 1^{2}$ while the developing nations are still struggling with a ratio of 5-12:1 ${ }^{3}$. The sustainable development goal number 3 aims at reducing the maternal mortality to 70/100,000 live births by $2030 .{ }^{4}$ The World Health Organization recently published near miss criteria to enable systematic data collection ${ }^{5}$. The prevalence of near miss is higher in developing countries and causes are similar to those of maternal mortality. Reviewing social causes of near miss cases provide significant information about the three delays in health system to identify its failures and assessment of quality of maternal health-care.

This study was conducted at a tertiary care center of North India which receives a high number of referrals. To our knowledge this is the first systematically conducted near miss and mortality audit of a large number of women admitted with PPH.

\section{Materials and methods}

The study was cross-sectional observational study conducted in a tertiary institute over one and half year (Nov 2014 to April 2016). The center caters to many nearby district hospitals and community hospitals providing round the clock emergency obstetric care. Ethical approval was obtained from institute's ethical committee before commencing the study. All the women who had PPH in the hospital or referred from outside with PPH were included in this study.

Maternal near miss women were identified on the basis of WHO 2009 criteria, according to which a maternal near miss case defined as "a woman who nearly died but survived a complication that occurred during pregnancy or within 42 days of termination of pregnancy". This included clinical, laboratory and management based criteria. During the same duration the maternal mortality was also evaluated and compared.

The method of blood loss estimation was visual assessment method. Blood loss of $500 \mathrm{ml}$ or more in vaginal deliveries and $1000 \mathrm{ml}$ or more in caesarean deliveries was used to define PPH.

All the details were recorded and analyzed using a structured proforma. Demographic details including age, parity, area of residence was noted. The level of education and number of antenatal visits were recorded. The place of delivery was recorded. Obstetrical risk factors like hypertension, multifetal pregnancy, obstructed labour, antepartum hemorrhage, jaundice, previous cesarean delivery and anemia were noted. Hypertension was defined as systolic blood pressure of $140 \mathrm{~mm} \mathrm{Hg}$ and diastolic BP of $90 \mathrm{~mm} \mathrm{Hg}$ and above on 2 occasions 4 hours apart. Severe anemia was defined as hemoglobin level of less than $7 \mathrm{~g} / \mathrm{dl}$ (as per Indian Council of Medical Research criteria) at admission/ time of $\mathrm{PPH}$. Causes of PPH mainly atonic, traumatic, retained placenta and coagulopathy were also noted.

The assessment of general condition was done. Low general condition was defined as a score of 8 or less on Glasgow coma scale (GCS). Obstetric shock index (OSI) was calculated as ratio of heart rate and systolic blood pressure. A study by Nathan et alin a higher resource setting used $\mathrm{OSI} \geq 1.7$ as cut off for intensive resuscitation ${ }^{6}$ and values of OSI $>1.7,1.3-1.7$ and $<1.3$ were taken as cut off for analysis. Management of the women including resuscitative measures like vasopressor support, blood transfusion and need for ventilator were recorded. Intervention done in form of repair of cervical tear, manual removal of placenta, uterine tamponade, compression suture on uterus, ligation of uterine artery and hysterectomy was documented. Involvement of other organ system resulting in acute renal failure, disseminated intravascular coagulation, acute respiratory distress syndrome were noted.

Social factors which could impact the quality of care including delay in seeking help due to lack of awareness, delay in transportation, lack of infrastructure, communication from where referred and non-availability of trained specialized health professionals in peripheral hospitals where the women were previously admitted, were noted.

Statistical analysis: The statistical analysis was done using SPSS (Statistical Package for Social Sciences) Version 15.0 statistical analysis software. Chi square test and student $t$ test were used for categorical and continuous data. $\mathrm{P}$ value of less than 0.05 was taken as significant.

\section{Results and observations}

The study was conducted over a period of one and half year from Nov 2014 to Apr 2016. The total deliveries during this period were 17,892 . The number of women enrolled with PPH during this period were 500. Of them 222 delivered in this hospital (incidence $1.2 \%$ ) and 278 women referred with $\mathrm{PPH}$ from nearby health centers, district hospitals and private hospitals. Mortality due to PPH was $84(16.8 \%)$ and number of maternal near miss were $85(17 \%)$. So the ratio of near miss to mortality in women with $\mathrm{PPH}$ was 1.01:1 in this audit. Out of the 84 women who expired, $38(45.2 \%)$ delivered in our hospital while $46(54.8 \%)$ delivered outside. Among the women with near miss 49 (57.6\%) delivered in our hospital while $36(42.4 \%)$ delivered 
outside. All the women who died and those who had near miss were compared in terms of demographic factors, social risk factors, obstetrical risk factors, types of $\mathrm{PPH}$ and interventions used. The demographic profile of the women was assessed and shown in table 1.

\begin{tabular}{llll} 
Table 1: Comparison of demographic factors in women with PPH & \multicolumn{2}{c}{ While $35(41.6 \%)$} \\
\hline Factors & $\begin{array}{l}\text { Mortality } \\
(\mathbf{N = 8 4 )}\end{array}$ & $\begin{array}{l}\text { Maternal near } \\
\text { miss (N=85) }\end{array}$ & $\begin{array}{l}\text { P } \\
\text { value }\end{array}$ \\
\hline Age in years & $26.5 \pm 4.21$ & $27.34 \pm 5.34$ & 0.27 \\
Multiparity (para 3 or above) & $31(36.90 \%)$ & $22(25.88 \%)$ & 0.16 \\
Illiteracy (women with less than primary education) & $64(76.19 \%)$ & $47(55.29 \%)$ & 0.007 \\
Rural & $57(67.85 \%)$ & $53(62.35 \%)$ & 0.45 \\
No ANC visits & $35(41.67 \%)$ & $29(34.11 \%)$ & 0.42 \\
\hline
\end{tabular}

On assessing the obstetrical risk factors associated with postpartum hemorrhage, near miss morbidity was more often seen in women with jaundice while maternal mortality was $52 / 85 ; 51 \%$ in women with near miss). 11 women had morbidly adherent placenta, of which 2/11(18.1\%) died

Table 2: Comparison of medical and obstetrical risk factors in maternal near miss \& mortality in women with PPH

\begin{tabular}{llllll}
$\begin{array}{lllll}\text { Parameters } \\
\text { Medical and } \\
\text { obstetrical risk factors }\end{array}$ & $\begin{array}{l}\text { Maternal mortality } \\
\text { Odd's }\end{array}$ & $\begin{array}{l}\text { 95\% Confidence } \\
\text { rnterval }\end{array}$ & $\begin{array}{l}\text { Maternal near miss } \\
\text { Odd's } \\
\text { ratio }\end{array}$ & $\begin{array}{l}\text { 95\% Confidence } \\
\text { interval }\end{array}$ & $\begin{array}{l}\text { P } \\
\text { value }\end{array}$ \\
\hline Severe anemia & 2.35 & $1.58-3.61$ & 1.3564 & $0.8451-2.177$ & $0.001^{*}$ \\
Antepartum hemorrhage & 19.24 & $6.2-59.3$ & 12.15 & $3.76-39.23$ & 0.279 \\
Hypertension & 1.36 & $0.66-2.82$ & 1.20 & $0.57-2.55$ & 0.793 \\
Obstructed labour & 12.22 & $1.25-119$ & 8.05 & $0.72-89.8$ & 0.640 \\
Jaundice & 11.51 & $2.98-44.40$ & 31 & $9.05-109.42$ & $0.023^{*}$ \\
Previous caesarean & 0.4148 & $0.0947-1.8159$ & 2.6644 & $1.2653-5.6104$ & $0.003^{*}$ \\
\hline *p value significant & & & & & \\
\hline
\end{tabular}

Table 3: Comparison of social risk factors in women with PPH and maternal outcome

\begin{tabular}{llllll}
\hline Social risk factors & \multicolumn{4}{c}{ Maternal outcome } & \multirow{2}{*}{ P value } \\
\cline { 2 - 5 } & \multicolumn{1}{c}{ Maternal mortality } & Maternal near miss & \\
\cline { 2 - 5 } & $\begin{array}{l}\text { Odd's } \\
\text { ratio }\end{array}$ & $\begin{array}{l}\mathbf{9 5 \%} \text { interval } \\
\text { intence }\end{array}$ & $\begin{array}{l}\text { Odd's } \\
\text { ratio }\end{array}$ & $\begin{array}{l}\mathbf{9 5 \%} \text { Confidence } \\
\text { interval }\end{array}$ & \\
\hline Lack of awareness & 4.63 & $2.43-8.83$ & 1.23 & $0.74-2.06$ & $<0.001^{*}$ \\
Lack of transport & 7.59 & $4.48-12.86$ & 1.77 & $1.05-2.98$ & $<0.001^{*}$ \\
Lack of infrastructure in health facilities & 5.30 & $3.18-8.82$ & 0.62 & $0.31-1.24$ & $<0.001^{*}$ \\
Lack of trained health professional & 7.35 & $4.2-12.6$ & 2.37 & $1.30-4.34$ & $<0.001^{*}$ \\
\hline$*$ p value significant & & & & &
\end{tabular}
while $9 / 11(81.8 \%)$ had near miss event. Repair of tear was done in 18 women in each group; uterine tamponade was done in 8 of 84 women who died as compared to 12 of 85 women who had near miss event. Surgical intervention including hysterectomy was done in 18 women who died and 22 women with near miss event $\quad(p=0.28)$. Systemic involvement was higher among women who died but not statistically significant (12/84vs 7/85; $\mathrm{p}=0.12$ ). As the women who died needed vasopressor and ventilator $* \mathrm{p}$ value significant

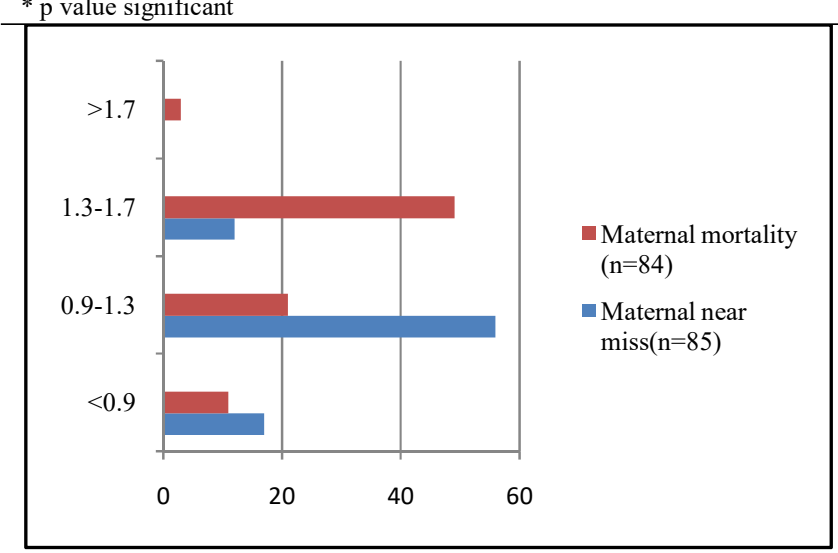

Figure 1: Comparison of OSI for maternal near miss and mortality seen more frequently in women with antepartum hemorrhage, obstructed labor and hypertensive disorders. Anemia was highly prevalent in women who died. Women support as compared to $45 / 85$ women with near miss event $(\mathrm{p}<0.001)$. Women with PPH with GCS score $>8$ had more near miss as compared to women who died $(47 / 84 ; 55.9 \%$ vs $17 / 85 ; 20 \% \mathrm{p}$ value $<0.001)$. When the obstetric shock index was compared OSI more than 1.7 was seen only in 3 women and all of them died. OSI of 1.3-1.7 was seen in $49 / 84$ $(58.33 \%)$ women who died as compared to $12 / 85(14.11 \%)$ who had near miss. OSI less than 1.3 was seen in $73 / 85(85.88 \%)$ women with near miss and 32/84 (38.09\%) women who died which was found to be clinically significant ( $\mathrm{p}$ value $<0.001)$ as shown in figure1. On analyzing social factors lack of awareness, timely referrals and availability of trained health professionals with proper facilities available to take care of women with $\mathrm{PPH}$ significantly affected the survival chances of the women as shown in table 3. 


\section{Discussion}

The present near miss and mortality audit of women with PPH is one of the largest audits in a low income country. This audit showed incidence of PPH to be $1.23 \%$. This audit also includes a large number of women who were referred with PPH in low general condition. Among the various demographic factors, illiteracy was s significant contributor to maternal mortality. This audit assessed various medical risk factors responsible for $\mathrm{PPH}$ of which anemia was highly prevalent in women who died, although it is difficult to comment whether anemia was pre-existent or developed as a consequence of PPH. Jaundice and previous cesarean were found to be significantly associated with near miss. The social risk factors highlighted the need for development of better health infrastructure and referral system with good transportation facilities for improved maternal outcome. A high maternal near miss to mortality ratio observed in this audit points out the existing lacunae in the health system and the scope for further improvement.

The incidence of PPH was similar to the incidence observed by Umashankar et al in a tertiary care hospital in Bangalore in 2014-16 which was $1.07 \%{ }^{7}$. However, Kaul et al reported a much lower incidence of PPH $(0.6 \%)$ in the study conducted at PGIMER, Chandigarh in $2006^{8}$. Higher incidence of PPH in this center could be due to a large number of women referred with obstetric complication and medical disorders like jaundice.

In this study the commonest cause of PPH was uterine atony seen in $68.4 \%$ of women. This is similar to the findings of Bateman et al in 2004 who found that PPH complicated $2.9 \%$ of all deliveries and uterine atony was the cause in $79 \%$ of cases ${ }^{9}$. However, the study conducted by Dongol AS et al in Nepal showed retained placenta as a cause of $\mathrm{PPH}$ in $61.7 \%$ of the cases which could be due to high number of home deliveries. ${ }^{10}$

In this study, OSI was used to predict adverse outcome in women with PPH, and showed that when OSI was more than 1.3, two-thirds of the women expired. A study conducted by El Ayadi et al in 2016 while evaluating the role of shock index in adverse maternal outcome found that a threshold of OSI $>0.9$ had high sensitivity but low specificity. ${ }^{11}$

This audit showed that of women referred with PPH, 30 women had home delivery. Among them 8/30women (26.7\%) died and 7/30 women had near miss (23.4\%). In a study conducted by Gantra et al in rural Maharashtra, India it was found that nearly half the women $(46.5 \%)$ died outside of a health facility $(26.4 \%$ at home, $6.6 \%$ in transit from home to a health facility, and $11.5 \%$ on the way from one facility to another) following home delivery. ${ }^{12}$

Analysis of the social factors showed a large contribution made by lack of awareness, lack of transportation, inadequate infrastructure and lack of trained health professional in leading to adverse maternal outcome in women with PPH. Fawcus et al in Zimbabwe found that delay in seeking treatment contributed to 32 percent and 28 percent of rural and urban deaths, respectively. Lack of transportation either delayed or prevented access to health facilities in the rural area leading to a major problem in 28 percent of the cases studied. Further suboptimal clinic and hospital management was identified in 67 percent and 70 percent of rural and urban deaths, respectively. ${ }^{13}$

To our knowledge this is one of the largest near miss and mortality audit of women with PPH. This study has evaluated the medical as well as obstetrical risk factors which have contributed to morbidity and mortality due to PPH. In low income nations social factors like lack of awareness, lack of infrastructure and transportation which play a large role in PPH have also been studied. However, this audit does not truly reflect the available health facilities at tertiary center due to following 2 factors - firstly a large number of women were referred with $\mathrm{PPH}$ in poor general condition. Despite best efforts the maternal outcome remained dismal. Secondly many medical factors leading to PPH were ascertained only on the basis of verbal communication due to absence of documentation along with referral. This could have a bearing on the actual assessment of the risk factors associated with PPH.

\section{Conclusion}

The present audit comprising of 500 women is one of the largest audits done so far. PPH is one of leading cause of maternal mortality in India. It gains relevance as one of the preventable causes of maternal mortality and morbidity. Recently focus has shifted from evaluation of maternal deaths to factors responsible for maternal near miss. In this study, the ratio of maternal near miss to maternal mortality is 1.01:1which points towards the urgent need to work towards corrective measures for improving the health facilities at peripheral level.

Comparison of near miss audit compared to maternal mortality audit provides us way of evaluating missed opportunities. It allows us to understand the steps that should be taken towards removing the obstacles. From this study we can conclude that proper antenatal bookings, early recognition of complications, reaching health care at time 
The New Indian Journal of OBGYN. 2021 (July-December);8(1)

and delivery of high-risk cases in institutes better equipped for intensive care are just a few steps that could be milestones in improving maternal outcomes and achieving health for all.

\section{Conflict of interest: None. Disclaimer: Nil.}

\section{References}

1. Amy JJ. Severe postpartum hemorrhage: A rational approach. Natl Med J India.1998;11:86-8.

2. Carroli G, Cuesta C, Abalos E, Gulmezoglu AM. Epidemiology of postpartum hemorrhage: a systematic review. Best practice\& research Clinical obstetrics \&gynaecology. 2008 Dec 31; 22(6):999-1012.

3. van Roosmalen J, Zwart J. Severe acute maternal morbidity in high-income countries. Best Practice and Research: Clinical Obstetrics and Gynaecology. 2009;23(3):297-304.

4. Prual A, Huguet D, Garbin O, Rabé G. Severe obstetric morbidity of the third trimester, delivery and early puerperium in Niamey (Niger). African Journal of Reproductive Health. 1998;2(1):10-19

5. SDG 3: Ensure healthy lives and promote wellbeing for all at all ages [Internet]. World Health Organization. 2015. Available from: https://www.who.int /sdg targets/en/

6. Say L, Souza JP, Pattinson RC. WHO working group on Maternal Mortality and Morbidity classifications. Maternal near miss - Towards a standard tool for monitoring quality of maternal health care. Best Pract Res Clin Obstet Gynaecol. 2009;23:287-96.

7. Umashankar KM, Dharmavijaya MN, Sudha R, Sujatha ND, Kavitha G. Effect of a Primary Postpartum Haemorrhage on the "Near-Miss" Morbidity and Mortality at a Tertiary Care Hospital in Rural Bangalore, India. Journal of clinical and diagnostic research: JCDR. 2013 Jun;7(6):1114.

8. Kaul V, Bagga R, Jain V, Gopalan S. The impact of primary postpartum hemorrhage in" near-miss" morbidity and mortality in a tertiary care hospital in North India. Indian journal of medical sciences. 2006 Jun 1; 60(6):233.

9. Bateman BT, Berman MF, Riley LE, Leffert LR. The epidemiology of postpartum hemorrhage in a large, nationwide sample of deliveries. Anesthesia \& Analgesia. 2010 May 1;110(5):1368-73.

10. Dongol AS, Shrestha A, Chawla CD. Post partum hemorrhage: Prevalence, morbidity and management pattern in Dhulikhel Hospital. Kathmandu University Medical Journal. 2010;8(2):212-5

11. El Ayadi AM, Nathan HL, Seed PT, Butrick EA, Hezelgrave NL, Shennan AH, Miller S. Vital Sign Prediction of Adverse Maternal Outcomes in Women with Hypovolemic Shock: The Role of Shock Index. PloS one. 2016 Feb 22;11(2):e0148729.

12. Ganatra BR, Coyaji KJ, Rao VN. Too far, too little, too late: a community-based case-control study of maternal mortality in rural west Maharashtra, India. Bulletin of the World Health Organization. 1998;76(6):591.

13. Fawcus S, Mbizvo M, Lindmark G, Nystrom L. A community-based investigation of avoidable factors for maternal mortality in Zimbabwe. Studies in Family planning. 1996 Nov 1:319-27.

\footnotetext{
Manu Shukla ${ }^{1}$, Vinita Das ${ }^{2}$, Smriti Agrawal ${ }^{3}$, Anjoo Agarwal ${ }^{4}$, Amita Pandey ${ }^{5}$

${ }^{1}$ Senior Resident, Department of Obstetrics \& Gynecology King George's Medical University, Lucknow, India; ${ }^{2}$ Professor and Head of Department, Department of Obstetrics \& Gynecology, King George's Medical University, Lucknow, India; ${ }^{3}$ Additional Professor, Department of Obstetrics \& Gynecology, King George's Medical University, Lucknow, India;

${ }^{4}$ Professor,Department of Obstetrics \& Gynecology, King George's Medical University, Lucknow, India;

${ }^{5}$ Professor, Department of Obstetrics \& Gynecology, King George's Medical University, Lucknow, India.
} 